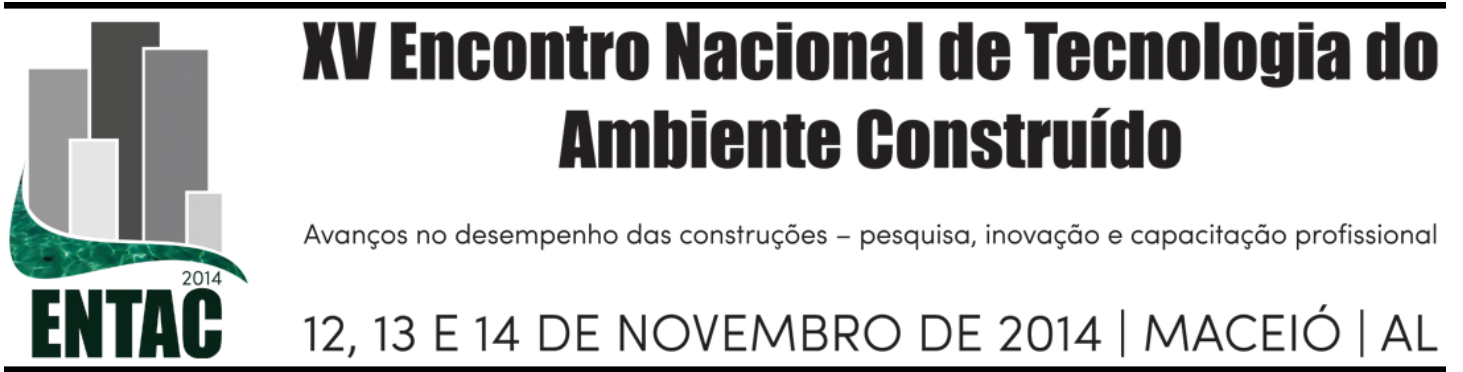

\section{O USO DO SINAPI PARA A ESCOLHA TECNOLÓGICA EM HABITAÇÕES POPULARES}

TANNENBAUM, Paulo Roberto Kozlowski (1); OLIVEIRA, Tatiana Thomé (2)

(1) Caixa, e-mail: paulo.t.filho@caixa.gov.br (2) Caixa, e-mail:

tatiana.t.oliveira@caixa.gov.br

\begin{abstract}
RESUMO
O objetivo prioritário desse trabalho é comparar soluções com diferentes níveis de industrialização para balizar a escolha quanto ao processo construtivo mais vantajoso a ser adotado. A CAIXA está aprimorando o SINAPI - Sistema Nacional de Pesquisa de Custos e Índices da Construção Civil, balizador oficial de custos para obras executadas com recursos Federais. Neste processo estão sendo aferidas 5.000 composições de serviço por meio de pesquisa em campo para a coleta, processamento e análise de informações quanto à eficiência na produção de obras. Esse trabalho tem focado também a criação de novas composições referentes a processos construtivos inovadores. O resultado já alcançado trouxe elementos para a proposição de um método para a comparação preliminar entre custos de soluções construtivas com nível de industrialização superior e de soluções convencionais. Os elementos empregados para esta comparação estão relacionados ao custo direto da parcela da construção, conforme escolha tecnológica, incluindo a demanda de mão de obra por unidade de serviço, e ao prazo e custos administrativos para a gestão da obra. Alguns dos parâmetros foram determinados através da análise das informações resultantes da aferição das composições do SINAPI e outros foram obtidos a partir de estudo comparativo realizado em orçamento e cronograma de projeto referencial do programa Minha Casa Minha Vida, simulando-se os impactos da adoção das diferentes tecnologias. Por fim, esse trabalho apresenta o SINAPI como ferramenta de fácil uso, tanto para construtores, como para fornecedores e desenvolvedores de processos construtivos, para estudar viabilidade e balizar decisões quanto ao processo a ser empregado, buscando a otimização de recursos na construção de edificações.
\end{abstract}

Palavras-chave: SINAPI, Custos, Produtividade.

\begin{abstract}
The primary purpose of this study is to compare solutions with different levels of industrialization, to guide the choice as to the most advantageous construction process to be adopted. CAIXA is enhancing SINAPI - National System of Costs for Civil Construction -, the official benchmark of costs for construction performed through federal resources. In this process, 5,000 compositions are being updated through field data collection, processing and analysis of information on the efficiency in the production of the built environment. This work is also focused on the creation of new
\end{abstract}


compositions regarding new construction processes. The results already achieved brought elements to propose a method for preliminary comparison between costs of constructive solutions with higher industrialization and conventional ones. The elements used for this comparison are related to the direct cost of the parcel of the construction for each technology choice, the demand for labor per unit of service, and the time and administrative costs for managing the work. Some of the parameters were determined by analyzing the information derived from the enhancements of SINAPI and others were obtained from a comparative study on budget and schedule, based on a reference project typically used on Minha Casa Minha Vida government program, simulating the impacts of adopting different technologies. Lastly, this work presents SINAPI as an easy to use tool for both builders and developers of new construction processes, to analyze feasibility and mark out decisions regarding which procedure to be employed, on the pursue of the optimization of resources in the construction industry.

Keywords: SINAPI, costs, production efficiency.

\section{INTRODUÇÃO}

A indústria da construção Brasileira é criticada com frequência por não atingir os mesmos níveis de desenvolvimento tecnológico dos demais ramos da indústria no País. Essa diferença não é percebida nos países industrializados, e apresentou sensível diminuição na última década nas demais economias em desenvolvimento, como China e Índia, onde é crescente o emprego da pré-fabricação e montagem, e outras técnicas menos dependentes de mão de obra, que tendem a reduzir os riscos de superação de custos e prazos planejados.

As críticas ao setor alcançam, além da construção propriamente dita, as etapas de projetos e orçamentos, em especial pelos baixos índices de investimento nessas fases, normalmente abrindo mão de planejamento e monitoramento mais apurado, caminho obrigatório para a industrialização do processo e aplicação de princípios de economia, precisão, qualidade e velocidade de um sistema de construção.

A escolha por determinado processo construtivo precisa considerar, além da diferença de custos entre resultados de desempenho equivalente, os impactos no contexto geral da obra, levando também em conta itens de relação indireta, tais como: otimização das instalações do canteiro, redução das interferências entre serviços, redução da mão de obra alocada e dos encargos incidentes, custos indiretos de administração da obra, controle de qualidade, e a existência de quantidade menor de pacotes de trabalho a serem gerenciados no empreendimento. Se a análise de viabilidade não contemplar esses efeitos e ainda forem adicionados custos relacionados às incertezas envolvidas por se tratar de inovação, possivelmente a escolha será pela manutenção das técnicas convencionais. O setor da indústria da construção civil no País se encontra em estágio com enorme potencial para inovação, por apresentar altos índices de perdas de materiais e por utilizar primordialmente processos de baixa produtividade.

As obras de edificações, em especial aquelas voltadas ao segmento de baixa renda, apresentam características do processo industrial: padronização e escala. Essas obras, usualmente subsidiadas com recursos públicos, apresentam pequena margem de lucro ao construtor, o que fomenta a implantação de técnicas construtivas que agreguem velocidade de execução, e redução e controle de custos e prazos.

Com a finalidade de contribuir para o melhor domínio dos custos e para a seleção de soluções tecnológicas, o presente estudo propõe uma metodologia para utilização de 
dados médios de produtividade e preço para subsidiar estudos comparativos de viabilidade entre métodos construtivos.

\section{METODOLOGIA DE ESTUDO}

O SINAPI - Sistema Nacional de Pesquisa de Custos e Índices foi criado em 1969 pelo Banco Nacional de Habitação - BNH - em parceria com o Instituto Brasileiro de Geografia e Estatística - IBGE. Em 1986, com a extinção do BNH, a Caixa Econômica Federal passou a ser responsável pelas atribuições do Banco na gestão do sistema criação, especificação, manutenção e publicação das composições unitárias de serviços e projetos referenciais, ou seja, base técnica de engenharia do SINAPI -, permanecendo o IBGE com a responsabilidade pela pesquisa mensal de preços dos insumos (materiais, mão de obra, equipamentos) nas 27 capitais brasileiras e formação de índices.

As composições de serviço do SINAPI, aproximadamente 3.400 referências publicadas mensalmente no sítio da CAIXA na internet (www.caixa.gov.br/sinapi), passam atualmente por processo de aferição, que resultará em atualização e ampliação do banco visando à incorporação de novos insumos e técnicas construtivas. $\mathrm{O}$ trabalho vem sendo realizado pela CAIXA, com o auxílio da FDTE - Fundação para o Desenvolvimento Tecnológico da Engenharia, sob a coordenação do prof. Dr. Ubiraci Espinelli (USP) e com a participação de importantes pesquisadores do País, desde janeiro de 2013 e tem término planejado para dezembro de 2017.

As premissas e metodologia empregadas nesse trabalho, bem como os conceitos básicos que norteiam a mensuração dos coeficientes de consumo e produtividade aferidos, foram apresentados em artigo intitulado "Sinapi em revisão", publicado na revistas Infraestrutura e Construção e Mercado (Editora PINI) do mês de fevereiro de 2014, e seguem fundamentação teórica apresentada em tese de Espinelli (1996).

O processo tem por objeto a aferição de 5.000 composições de serviço por meio de pesquisa em campo para a coleta, processamento e análise de informações quanto à eficiência na produção de obras. Os resultados obtidos são fruto de estudo estatístico aplicado a amostras de representatividade nacional coletadas em obras distribuídas em nove praças: Florianópolis, São Paulo, São Carlos, Brasília, Goiânia, Teresina, São Luís, Salvador e Fortaleza. O estudo detalhado dos serviços já aferidos nesse trabalho trouxe elementos importantes para comparativo entre recursos necessários e custos de soluções construtivas com diferentes graus de industrialização.

Os indicadores propostos para esta comparação são: o custo direto da parcela da construção, conforme escolha tecnológica, e a demanda de mão de obra por $\mathrm{m}^{2}$ de construção, ambos determinados através da análise das composições unitárias resultantes da aferição das composições do SINAPI, que representam a atualização mais recente quanto ao estudo da eficiência na produção de obras no Brasil.

\section{SERVIÇOS ESTUDADOS}

A escolha dos serviços a serem estudados foi baseada na freqüência e relevância desses nos orçamentos de empreendimentos do Programa Minha Casa Minha Vida - PMCMV, programa governamental voltado ao segmento de baixa renda iniciado em 2009, que apresenta a meta de contratação de três milhões de unidades habitacionais até final de 2014. Os serviços estudados são os de execução de chapisco e massa única em fachada.

Cabe ressaltar que o SINAPI é parte da formação do preço de uma intervenção. O processo de orçamentação passa pela identificação e particularização para o caso 
específico em análise, por meio de combinações apropriadas das composições referenciais apresentadas, que poderão ser devidas às especificidades do projeto, às condições locais de execução, aos requisitos de contratação, entre outros. Ainda há de se considerar na formação do preço outros itens como aqueles relacionados à administração local (canteiro, mobilização e desmobilização, encargos complementares, etc.), despesas e custos indiretos, além do lucro do construtor.

Por isso, para o desenvolvimento do estudo piloto foi escolhida uma obra paradigma de tipologia típica do PMCMV, com condições e especificações bem definidas, para que o comparativo tenha a devida validade.

\subsection{Chapisco}

A NBR 13529/2013 - Revestimento de paredes e tetos de argamassas inorgânicas — Terminologia, conceitua sistema de revestimento, sendo suas partes: base ou substrato, camada de preparo (chapisco) e revestimento de argamassa. O chapisco é a camada de preparo da base, aplicada de forma continua ou descontinua, com a finalidade de uniformizar a superfície quanto à absorção e melhorar a aderência do revestimento. Esta finalidade é evidenciada quando se analisam os diferentes elementos de uma fachada a ser revestida, onde podem estar presentes blocos de alvenaria, argamassa de assentamento e estrutura de concreto armado, por exemplo. Esses elementos diferem quanto à porosidade e rugosidade, exigindo que o chapisco realmente homogeneíze a base, permitindo a adequada aplicação da argamassa de revestimento.

Os chapiscos podem ser categorizados quanto a dois parâmetros: materiais componentes (cimento, agregado e água), denominados de convencionais, ou com acréscimo de polímeros, denominados modificados; e forma de aplicação/técnica utilizada (com colher, rolado, desempenado ou projetado), conforme Figura 1. A qualidade final do chapisco executado está relacionada à atenção aos seguintes itens: qualidade do preparo da base, qualidade dos insumos (cimento, agregados, água e polímeros), processo de produção ou mistura da argamassa (no caso de industrializada), forma correta de aplicação e manutenção das condições ambientais adequadas para cura. Se todos esses itens forem seguidos corretamente, as diferentes formas de aplicação apresentarão desempenho adequado quanto à aderência à base.

\section{Figura 1 - Formas de aplicação do chapisco}

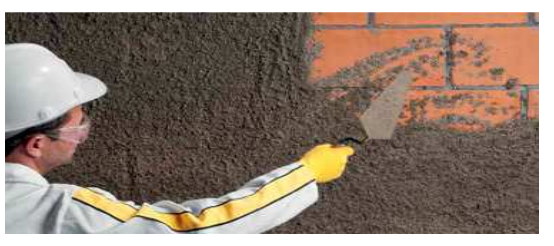

Aplicação com colher de pedreiro

Fonte: www.weber.com.br

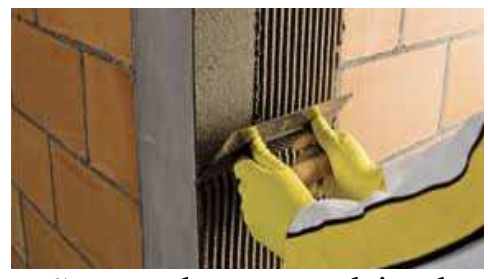

Aplicação com desempenadeira denteada Fonte: www.weber.com.br

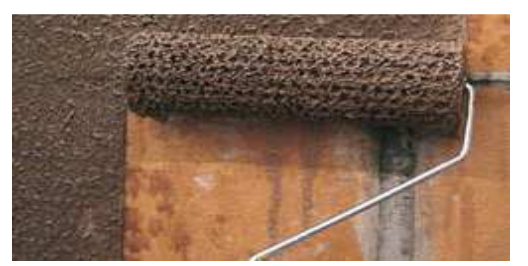

Aplicação com rolo para textura acrílica Fonte: www.weber.com.br

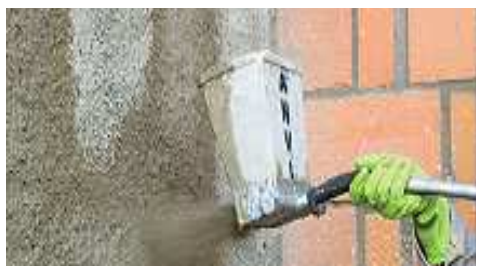

Aplicação com equipamento de projeção Fonte: www.techne.pini.com.br 
O chapisco aplicado manualmente com colher de pedreiro emprega usualmente argamassa na proporção volumétrica 1:4 de cimento e areia, e exige do operário o controle da energia de lançamento para garantir a aderência da argamassa ao substrato. O chapisco rolado é aplicado com rolo de espuma próprio para textura, podendo ser empregada argamassa preparada em obra com adição de polímero ou industrializada. $\mathrm{O}$ chapisco desempenado é executado com desempenadeira denteada, somente com emprego de argamassa industrializada (argamassa colante), e apenas em estruturas de concreto. O chapisco projetado utiliza a mesma argamassa aplicada com colher de pedreiro, além de equipamento de projeção composto por um compressor, que pode ser a diesel ou elétrico, e uma pistola com recipiente acoplado, denominada de "canequinha".

Além da forma de aplicação do chapisco, as composições do SINAPI aferidas para as fachadas consideram outro fator que impacta significativamente nos coeficientes de produtividade e consumos, e está associado à dificuldade de execução dos serviços: fachada sem vãos (pano cego) e fachada com vãos, quando é incluído o esforço para execução de quinas e requadros. As combinações disponibilizadas nas composições do SINAPI estão apresentadas na Figura 2 - árvore de composições.

\section{Figura 2 - Árvore de Composições de Chapisco na Fachada}

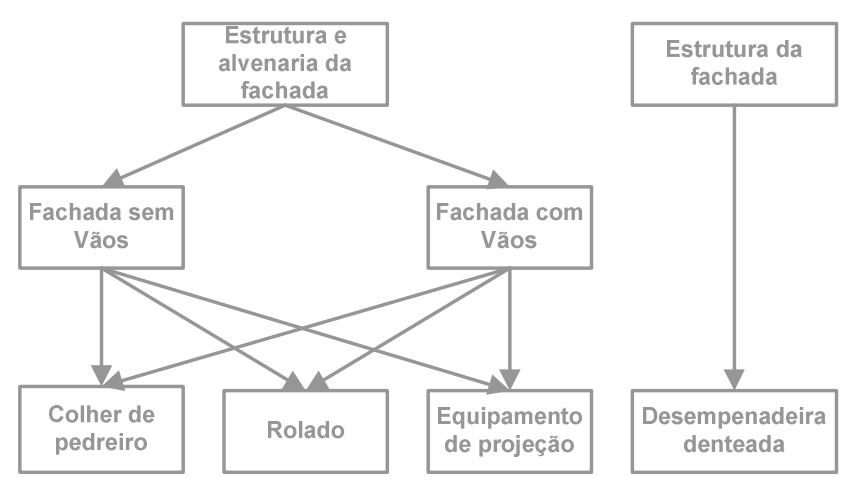

\subsection{Massa única}

Conforme a NBR 13529/2013, o revestimento de argamassa é o cobrimento de uma superfície com uma ou mais camadas superpostas de argamassa, apto a receber acabamento decorativo ou constituir-se em acabamento final. Segundo Baía e Sabbatini (2001, p. 13), a finalidade do revestimento é auxiliar os elementos de vedação no desempenho termo-acústico e de estanqueidade.

Os revestimentos à base de argamassa podem ser aplicados de forma manual ou mecanizada. Para a aplicação mecanizada podem ser empregados dois tipos de equipamentos: bombas de mistura e projeção, e a "canequinha" - pistola spray com recipiente acoplado. A canequinha permite a utilização tanto de argamassa industrializada quanto dosada em obra, por sua vez, é recomendável a utilização de argamassa industrializada para as bombas.

A exemplo das composições de chapisco, as composições de massa única em fachadas são diferenciadas em função da dificuldade de execução do serviço: fachada sem vãos (pano cego), fachada com vãos, sacada interna e sacada externa. A Figura 3 apresenta detalhes sobre essas diferentes situações. As combinações disponibilizadas nas composições do SINAPI estão apresentadas na árvore de composições da Figura 4. 
Figura 3 - Local de aplicação do revestimento

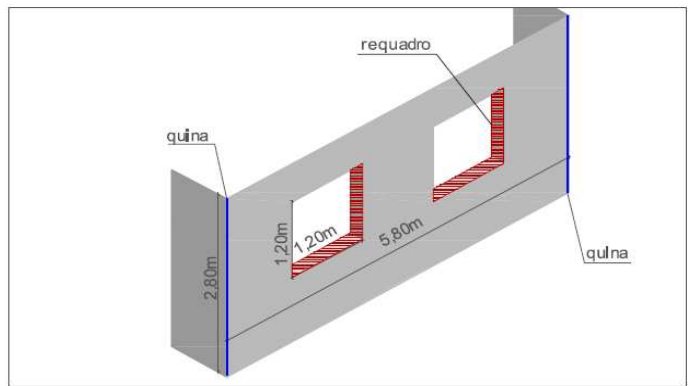

Pano com vãos

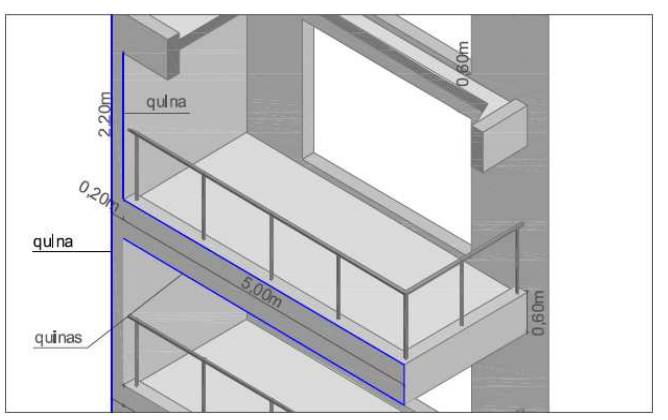

Superfícies externas da sacada

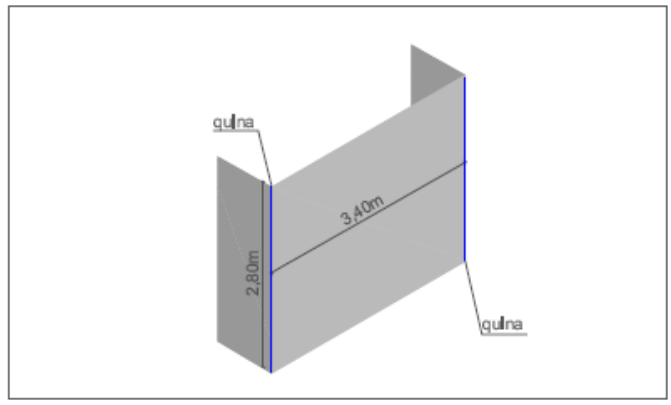

Panos sem vãos

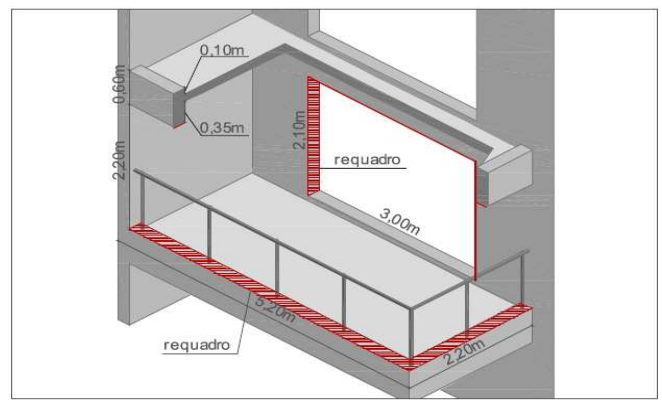

Superfícies internas da sacada

Figura 4 - Árvore de Composições de Massa única na Fachada

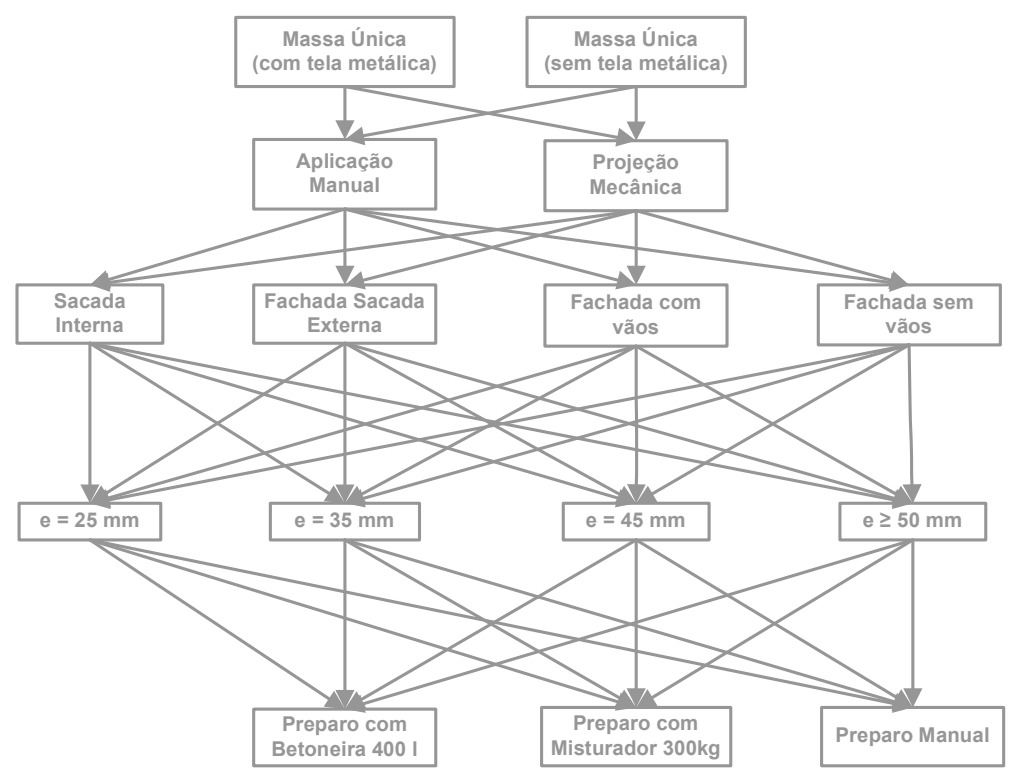

\section{ESTUDO PILOTO}

Para apresentar método que emprega o SINAPI como ferramenta para análise do impacto da adoção das diferentes tecnologias nos orçamentos, realizou-se estudo piloto em projeto referencial do PMCMV destinado a famílias com renda entre 4 e 10 salários mínimos. Essa tipologia é recorrente e representativa do setor de construções populares (a Figura 5 apresenta as plantas de elevação e cobertura). A edificação é projetada em 
alvenaria estrutural e é constituída de pavimento térreo mais três tipos, com quatro apartamentos por andar, sendo esses de dois dormitórios com área privativa de $55,53 \mathrm{~m}^{2}$. O estudo comparativo realizado analisa as seguintes opções construtivas: (A) chapisco com colher ou (B) chapisco rolado, e (C) massa única aplicada manualmente ou (D) massa única aplicada de forma mecanizada.

Os preços dos insumos empregados nas análises são referências do SINAPI para a localidade de São Paulo, data base FEV/2014 sem os efeitos da desoneração da mão de obra.

\section{Figura 5 - Plantas tipologia adotada Estudo Piloto}
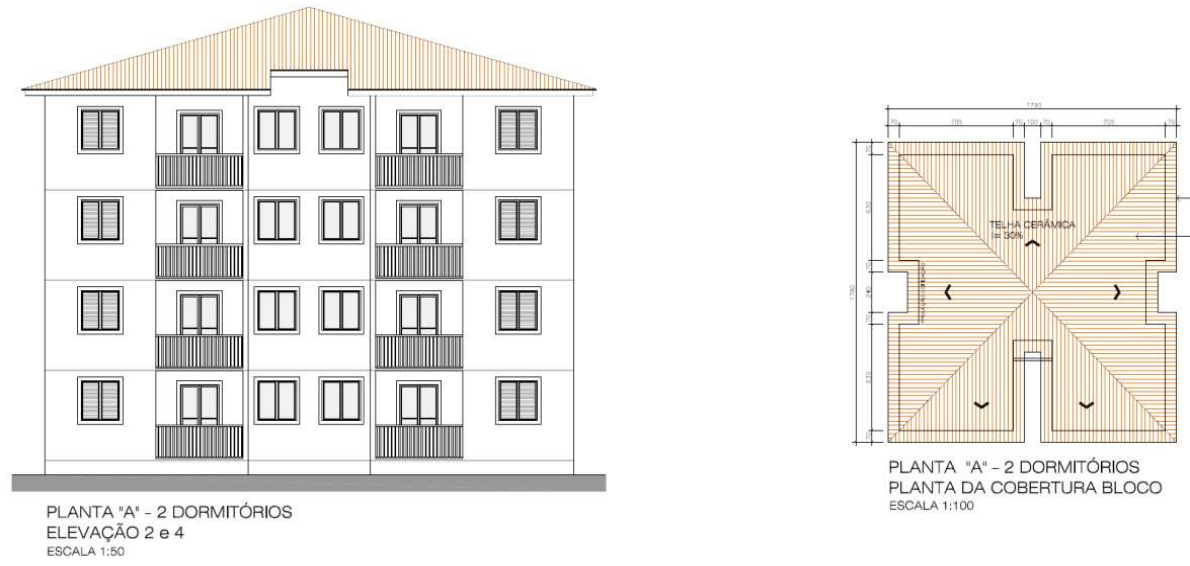

Para estudo do serviço de chapisco foram consideradas as áreas de fachada da edificação da Figura 5 agrupadas em: (i) com vão, que inclui as sacadas internas e externas) e (ii) sem vão, totalizando as áreas líquidas de $864,29 \mathrm{~m}^{2}$ e $237,98 \mathrm{~m}^{2}$, respectivamente. Adota-se, conforme previsto nos coeficientes das composições do SINAPI, que o serviço é executado com equipe formada por 2 oficiais e 1 servente e a jornada de trabalho de 7,33h diárias (44 horas semanais distribuídas em 6 dias).

O Quadro 1 apresenta as composições para execução de chapisco com colher (A) e rolado (B).

\section{Quadro 1 - Composições unitárias de chapisco}

\begin{tabular}{|c|c|c|c|c|c|c|c|c|c|}
\hline \multirow[b]{2}{*}{$\begin{array}{c}\text { Chapisco em } \\
\text { Fachada }\end{array}$} & \multicolumn{2}{|c|}{ Pedreiro } & \multicolumn{2}{|c|}{ Servente } & \multicolumn{2}{|c|}{$\begin{array}{l}\text { Argamassa p/ } \\
\text { chapisco rolado }\end{array}$} & \multicolumn{2}{|c|}{$\begin{array}{l}\text { Argamassa p/ } \\
\text { chapisco colher }\end{array}$} & \multirow{2}{*}{$\begin{array}{l}\text { Custo } \\
\mathbf{R} \$ / \mathrm{m}^{2}\end{array}$} \\
\hline & $h / m^{2}$ & $\mathbf{R} \$ / \mathbf{m}^{2}$ & $\mathbf{h} / \mathbf{m}^{2}$ & $\mathbf{R} \$ / \mathbf{m}^{2}$ & $\mathbf{m}^{3} / \mathbf{m}^{2}$ & $\mathbf{R} \$ / \mathbf{m}^{3}$ & $\mathbf{m}^{3} / \mathbf{m}^{2}$ & $\mathbf{R} \$ / \mathbf{m}^{3}$ & \\
\hline $\begin{array}{l}\text { Com vãos/ } \\
\text { colher }\end{array}$ & 0,183 & 12,88 & 0,091 & 10,59 & - & - & 0,004 & 295,90 & 4,56 \\
\hline $\begin{array}{l}\text { Sem vãos/ } \\
\text { colher }\end{array}$ & 0,124 & 12,88 & 0,062 & 10,59 & - & - & 0,004 & 295,90 & 3,50 \\
\hline Com vãos/ rolo & 0,108 & 12,88 & 0,054 & 10,59 & 0,001 & 1613,27 & - & - & 4,37 \\
\hline Sem vãos/ rolo & 0,073 & 12,88 & 0,036 & 10,59 & 0,001 & 1613,27 & - & - & 3,73 \\
\hline
\end{tabular}


O Quadro 2 apresenta os resultados da comparação entre indicadores resultantes da utilização dos dois métodos construtivos para a execução de chapisco para as fachadas do projeto referencial.

\section{Quadro 2 - Resultados Tecnologia X Projeto}

\begin{tabular}{|l|c|c|c|c|c|c|c|c|}
\hline $\begin{array}{c}\text { Método } \\
\text { Construtivo }\end{array}$ & \multicolumn{2}{|c|}{$\begin{array}{c}\text { Consumo de } \\
\text { Argamassa }\end{array}$} & \multicolumn{2}{c|}{$\begin{array}{c}\text { Custo de } \\
\text { Argamassa }\end{array}$} & \multicolumn{2}{c|}{$\begin{array}{c}\text { Demanda por Mão } \\
\text { de Obra }\end{array}$} & \multicolumn{2}{|c|}{ Custo Total } \\
\cline { 2 - 9 } & $\mathbf{m}^{\mathbf{3}}$ & var. \% & $\mathbf{R} \$$ & var \% & horas & var \% & R\$ & var \% \\
\hline (A) Colher & 4,63 & 0 & $1.369,88$ & 0 & 187,67 & 0 & $4.776,29$ & 0 \\
\hline (B) Rolo & 1,64 & $-64,52$ & $2.649,61$ & 93,42 & 110,72 & $-41,01$ & $4.660,61$ & $-2,42$ \\
\hline
\end{tabular}

Os resultados apontam para a escolha do chapisco com rolo, por representar custo $2,42 \%$ menor (apesar do custo $93,42 \%$ maior da parcela de argamassa) e demandar $41,01 \%$ menos mão de obra. Segundo o número de horas demandadas, uma equipe executa o serviço em 12,8 dias no caso (A) e em 7,5 dias no caso (B), o que, além de reduzir o custo com a parcela de mão de obra do serviço resulta na diminuição dos custos indiretos devido à redução do prazo de execução do serviço, com consequente redução de encargos complementares, custos com a manutenção da administração local e outros custos indiretos.

Para estudo do serviço de massa única foram consideradas as áreas de fachada da edificação da Figura 5 agrupadas em: (i) com vão, (ii) sem vão, (iii) sacadas externas e (iv) sacadas internas, totalizando as áreas líquidas de $573,81 \mathrm{~m}^{2}, 237,98 \mathrm{~m}^{2}, 80,79 \mathrm{~m}^{2}$, $209,69 \mathrm{~m}^{2}$, respectivamente. Para todos os casos, as demais variáveis das composições (conforme árvore do Grupo - Figura 4) foram mantidas constantes: revestimento de massa única executado com tela metálica e de espessura de $25 \mathrm{~mm}$. A argamassa empregada para ambos os casos é a mesma (traço 1:2:8, dosada em betoneira de 4001). Para a aplicação mecanizada foi considerado o uso do equipamento de projeção do tipo "canequinha", sendo seu preço de locação obtido junto à empresa especializada no setor.

A partir dos coeficientes apresentados nas composições do Quadro 3, para os casos de execução de massa única com aplicação manual (C) e mecanizada (D), foram calculados os consumos totais de argamassa e de esforço de mão de obra para execução das fachadas do projeto Piloto. Quando comparados os casos tem-se: consumo de argamassa é o mesmo, enquanto a produtividade da mão de obra é $16 \%$ melhor no caso (D). $O$ custo é $1,2 \%$ menor no caso (D), mesmo agregados os custos de utilização do equipamento. Ainda nota-se que uma equipe (1 oficial e 1 servente) executa o serviço em 122,3 dias no caso (C) e em 102,6 dias no caso (D). Para este estudo, a redução do prazo de execução do serviço, com consequente redução de encargos complementares, custos com a manutenção da administração local e custos indiretos é o que torna a opção de mecanização mais atrativa.

A locação do equipamento de projeção é mensal, assim sendo é conveniente o emprego de duas ou quatro equipes, o que acarreta a necessidade de locação de dois equipamentos por período de dois meses (51,33 dias de duração do serviço) ou de quatro equipamentos por um mês (25,66 dias). Nessas duas condições, os equipamentos locados são melhor aproveitados. Os custos com o equipamento tendem a diminuir quando realizada comparação entre os custos de propriedade e o valor de aluguel. 


\section{Quadro 3 - Composições unitárias de massa única}

\begin{tabular}{|c|c|c|c|c|c|c|c|c|c|c|c|}
\hline \multirow[b]{2}{*}{$\begin{array}{l}\text { Massa Única } \\
\text { em Fachada } \\
\text { e=25mm }\end{array}$} & \multicolumn{2}{|c|}{ Pedreiro } & \multicolumn{2}{|c|}{ Servente } & \multicolumn{2}{|c|}{ Argamassa } & \multicolumn{2}{|c|}{ Tela } & \multicolumn{2}{|c|}{ Canequinha } & \multirow{2}{*}{$\begin{array}{l}\text { Custo } \\
\mathrm{R} \$ / \mathrm{m}^{2}\end{array}$} \\
\hline & $\mathbf{h} / \mathbf{m}^{2}$ & $\mathbf{R} / \mathbf{m}^{2}$ & $\mathbf{h} / \mathbf{m}^{2}$ & $\mathbf{R} / \mathbf{m}^{2}$ & $\mathbf{m}^{3} / \mathbf{m}^{2}$ & $\mathbf{R} / \mathbf{m}^{3}$ & $\mathbf{m}^{2} / \mathbf{m}^{2}$ & $\mathbf{R} / \mathbf{m}^{2}$ & $\mathbf{h} / \mathbf{m}^{2}$ & $\mathbf{R} / \mathbf{h}$ & \\
\hline $\begin{array}{l}\text { Com vãos/ } \\
\text { manual }\end{array}$ & 0,780 & 12,88 & 0,780 & 10,59 & 0,031 & 297,59 & 0,139 & 11,52 & - & 11,52 & 29,25 \\
\hline $\begin{array}{l}\text { Sem vãos/ } \\
\text { manual }\end{array}$ & 0,400 & 12,88 & 0,400 & 10,59 & 0,029 & 297,59 & 0,158 & 11,52 & - & 11,52 & 19,93 \\
\hline $\begin{array}{l}\text { Sacada ext./ } \\
\text { manual }\end{array}$ & 1,550 & 12,88 & 1,550 & 10,59 & 0,029 & 297,59 & 0,000 & 11,52 & - & 11,52 & 45,10 \\
\hline $\begin{array}{l}\text { Sacada int./ } \\
\text { manual }\end{array}$ & 1,090 & 12,88 & 1,090 & 10,59 & 0,036 & 297,59 & 0,000 & 11,52 & - & 11,52 & 36,27 \\
\hline $\begin{array}{l}\text { Com vãos/ } \\
\text { mecanizada }\end{array}$ & 0,650 & 12,88 & 0,650 & 10,59 & 0,031 & 297,59 & 0,139 & 11,52 & 0,650 & 3,97 & 28,78 \\
\hline $\begin{array}{l}\text { Sem vãos/ } \\
\text { mecanizada }\end{array}$ & 0,270 & 12,88 & 0,270 & 10,59 & 0,029 & 297,59 & 0,158 & 11,52 & 0,270 & 3,97 & 17,95 \\
\hline $\begin{array}{l}\text { Sacada ext./ } \\
\text { mecanizada }\end{array}$ & 1,410 & 12,88 & 1,410 & 10,59 & 0,029 & 297,59 & 0,000 & 11,52 & 1,410 & 3,97 & 47,41 \\
\hline $\begin{array}{l}\text { Sacada int./ } \\
\text { mecanizada }\end{array}$ & 0,960 & 12,88 & 0,960 & 10,59 & 0,036 & 297,59 & 0,000 & 11,52 & 0,960 & 3,97 & 37,03 \\
\hline
\end{tabular}

Quando confrontados com as especificidades de um projeto de tipologia típica do PMCMV, os dados do SINAPI demonstraram, para os dois serviços escolhidos, a vantagem da aplicação das técnicas que demandam menor quantidade de mão de obra, tanto sob a ótica de custo quanto de prazo.

\section{CONSIDERAÇÕES FINAIS}

Embora o estudo Piloto realizado tenha comparado a execução dos serviços de chapisco e massa única em apenas uma edificação isolada, observa-se que no caso do PMCMV é comum a concepção de grandes empreendimentos, com repetição de torres da mesma tipologia. Nesse caso torna-se ainda mais atrativo o emprego das técnicas de serviço mecanizadas, onde os ganhos financeiro e de prazo tornam-se mais expressivos.

O trabalho demonstra que as referências do SINAPI possibilitam uma série de análises além da apropriação de custo - uso tradicional das composições unitárias do Sistema tais como: a escolha da técnica mais vantajosa e do número de equipes a serem alocadas para a execução do serviço dentro de prazo estabelecido; melhor aproveitamento de equipamentos locados pela correta estimativa de duração das frentes de trabalho; definição do plano de ataque de obra pelo conhecimento da variação das demandas do serviço; dentre outras.

Os dados apresentados no SINAPI representam produtividade e preços de insumos médios de mercado. A análise de viabilidade de implantação de uma nova tecnologia construtiva no portfólio de uma empresa baseada em dados médios é conservadora, pois se sabe de antemão da possibilidade de obtenção de indicadores melhores à medida que se investe em treinamento de equipe e na gestão do processo. Por sua vez, o estudo será mais preciso caso o construtor utilize preços de insumos a que comprovadamente tenha 
acesso no mercado, que podem variar em função da política de suprimentos e fornecedores de cada empresa.

Cabe salientar, que o SINAPI é de acesso público e gratuito, sendo uma fonte sólida para embasar decisões gerenciais sobre as tecnologias a serem empregadas na execução dos serviços, oferecendo método para redução dos custos de execução de obras.

O estudo Piloto foi realizado com apenas dois serviços, dentre uma infinidade de processos existentes em construções e representados no SINAPI, o que indica o potencial de análises relativas ao planejamento de obras com base nas informações divulgadas no sistema.

\section{REFERÊNCIAS}

ASSOCIAÇÃO BRASILEIRA DE NORMAS TÉCNICAS (ABNT). NBR-13529:

Revestimentos de paredes e tetos de argamassas inorgânicas. Rio de Janeiro, 2013.

BAÍA, L. L. M.; SABBATINI, F. H. Projeto e execução de revestimento de argamassa: primeiros passos da qualidade no canteiro de obras. São Paulo, 2001.

OLIVEIRA, T.; SOUZA, U.; FILHO, P.; KATO, C.; Sinapi em revisão. Revista Infraestrutura Urbana, Editora PINI, Fev/2014.

SOUZA, U. E. L. . Metodologia para o estudo da produtividade da mão-de-obra no serviço de fôrmas para estruturas de concreto armado. Tese de doutorado. EPUSP. São Paulo. 1996

<http://www. http://www.weber.com.br/solucoes-tecnicas/produtos/chapiscar.html/>. Acesso em: 30 abr. 2014.

<http://techne.pini.com.br/engenharia-civil/158/revestimento-287750-1.aspx>. Acesso em: 30 abr. 2014 